\title{
Seasonal Variation in a Hymenopterous Parasitoid, Holcotetrastichus rhosaces (Walker) (Hymenoptera: Tetrastichinae), on Its Hosts, Cassida nebulosa L. and C. piperata Hope (Coleoptera: Chrysomelidae), in Sendai, Northeastern Area of Japan
}

\author{
Atsuhiko Nagasawa \\ Laboratory of Insect Science and Bioregulation, Graduate School of Agricultural Science, Tohoku University, \\ Sendai, Japan \\ Email: atsu.nagasawa@gmail.com
}

Received 20 June 2014; revised 24 July 2014; accepted 13 August 2014

Copyright (C) 2014 by author and Scientific Research Publishing Inc.

This work is licensed under the Creative Commons Attribution International License (CC BY).

http://creativecommons.org/licenses/by/4.0/

(c) (i) Open Access

\begin{abstract}
To investigate the seasonal variation of parasitism on Cassida nebulosa L. and C. piperata Hope, this research was conducted at the experimental field of Tohoku University in Sendai, Japan, where these tortoise beetles were parasitized by hymenopterous parasitoid Holcotetrastichus rhosaces (Walker). Percentage parasitism started to increase from the middle of July and reached nearly $100 \%$ in August. Adults of $H$. rhosaces emerged from the pre-pupae of the tortoise beetles, with 6 to 30 adults emerging per pre-pupae. The second generation of $C$. nebulosa and $C$. piperata was heavily parasitized by $H$. rhosaces. The adults of these tortoise beetles were rarely found in the field during late summer due to the high rates of parasitism.
\end{abstract}

Keywords

Tortoise Beetle, Wasp, Percentage Parasitism

\section{Introduction}

Cassida nebulosa L. is distributed from East Asia and Siberia to Europe (palaearctic region) and Cassida pipe-

How to cite this paper: Nagasawa, A. (2014) Seasonal Variation in a Hymenopterous Parasitoid, Holcotetrastichus rhosaces (Walker) (Hymenoptera: Tetrastichinae), on Its Hosts, Cassida nebulosa L. and C. piperata Hope (Coleoptera: Chrysomelidae), in Sendai, Northeastern Area of Japan Advances in Entomology, 2, 176-179. http://dx.doi.org/10.4236/ae.2014.24026 
rata Hope from eastern Siberia to East Asia and Southeast Asia [1] [2]. The beetles feed on chenopodiaceous and amaranthaceous plants. Cassida nebulosa is known as a pest of sugar beet. In Japan, the parasitoid wasp Brachymeria punctulata (Förster) has been recorded from C. nebulosa [3], where as Brachymeria inermis (Fonscolombe) and Holcotetrastichus rhosaces (Walker) have been recorded from both C. nebulosa and C. piperata [4]-[7]. However, details of the parasitism of these tortoise beetles in Japan have hitherto been unknown. In Europe, Domenichini described the literature on the biology of $H$. rhosaces; however, no further information was available [8]. Therefore, I investigated the parasitism of C. nebulosa and C. piperata in the experimental field of the Graduate school of Agricultural Sciences at Tohoku University in Sendai, Japan. In addition to determining when and how much parasitism occurred, I monitored how many adult wasps emerged from one beetle after the larvae were attacked by the parasitoid wasps.

\section{Materials and Methods}

The annual weeds Chenopodium album L. and Chenopodium album var. centrorubrum Makino are the hosts of C. nebulosa and C. piperata. Since C. album and C. album var. centrorubrum generally grow in open fields and are sensitive to human disturbances, they were alternately planted (30 plants of each species on $100 \mathrm{~m}^{2}$ ) in an experimental field at the Graduate School of Agricultural Science, Tohoku University (Sendai, Japan) on June 12, 2000 and May 21, 2001. The surrounding vegetation was removed. The numbers of C. nebulosa and C. piperataon the plants were counted every 1 or 2 weeks, from June to August over a 2-year period. The studies began on June 17, 2000 and on June 3, 2001. Parasitized larvae appear brown when they enter the prepupal stage (Figure 1). Percentage parasitism was calculated as the percentage of parasitized pre-pupae to the total number of non-parasitized pre-pupae, pupae, and recently emerged adults. Adults with light-colored bodies were considered to be recently emerged. To avoid repeat counting, the parasitized pre-pupae were removed. In 2003, the larvae of these beetles were collected and individually reared in plastic petri dishes to obtain the number of emerged wasps.

\section{Results and Discussion}

All of the wasps that parasitized C. nebulosa and C. piperata collected from the experimental field were identified as H. rhosaces (Walker). Holcotetrastichus rhosaces, which is widely distributed in Europe, has been recorded to parasitize seven species of the genus Cassida, including C. nebulosa [9], and in Japan, the wasp has been recorded from C. nebulosa, C. piperata, and C. japana [6] [7] [10].

Parasitized tortoise beetles turn brown and die at the prepupal stage. Six to 30 adult wasps emerged from the parasitized pre-pupae of $C$. nebulosa, whereas 4 to 25 adult wasps emerged from the parasitized pre-pupae of $C$. piperata. The average number of emerged adults was $12.4 \pm 5.95$ (mean $\pm \mathrm{SD}, \mathrm{N}=35$ ) and $10.6 \pm 5.21$ (mean \pm $\mathrm{SD}, \mathrm{N}=80$ ) in $C$. nebulosa and $C$. piperata, respectively. The parasitoid wasps emerged from the pupae collected at the first instar-larval stage, indicating that young tortoise beetle larvae are susceptible to attack by $H$. rhosaces. It is not clear whether mature larvae are attacked by $H$. rhosaces.

In the study region, both species of tortoise beetle appear from the end of May to the end of August, and during this season their larval populations show two peaks. This indicates that two generations of beetles are pro-

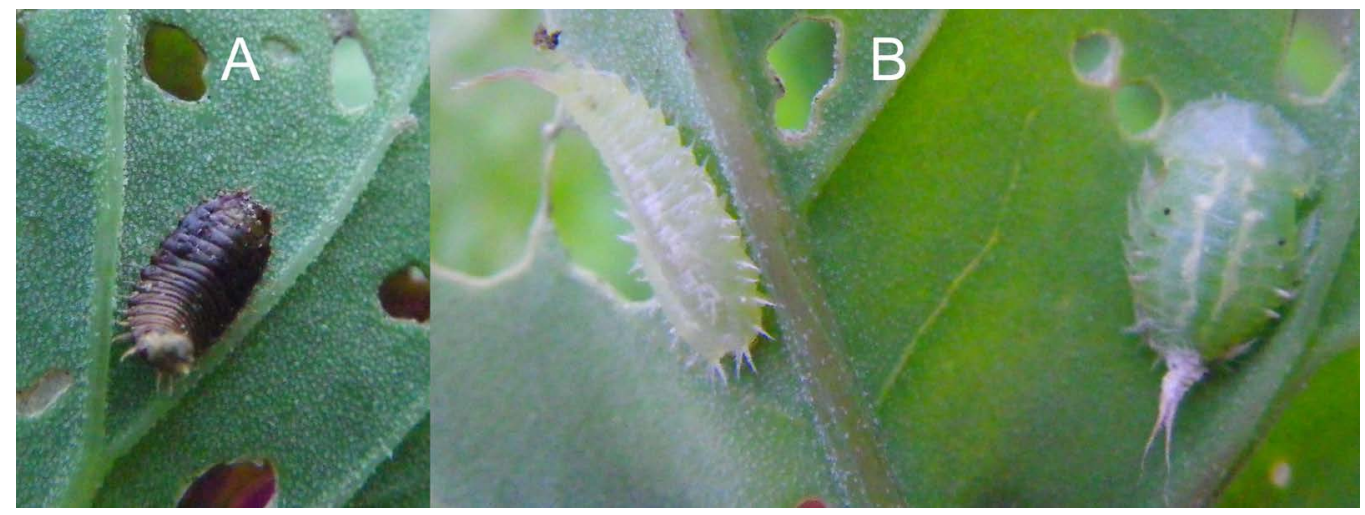

Figure 1. Cassida nebulosa. (A) Parasitized pre-pupa; (B) Non-parasitized pre-pupa (left) and pupa (right). 
duced annually. The number of C. nebulosa larvae was larger in the first generation (Figure 2), where as the number of C. piperata larvae was larger in the second generation (Figure 3). Despite these differences, the percentage parasitism of both species by $H$. rhosaces was higher later in the season. Nearly $100 \%$ of individuals of both beetle species were parasitized by $H$. rhosaces in the second generation (Figure 2, Figure 3). Due to the
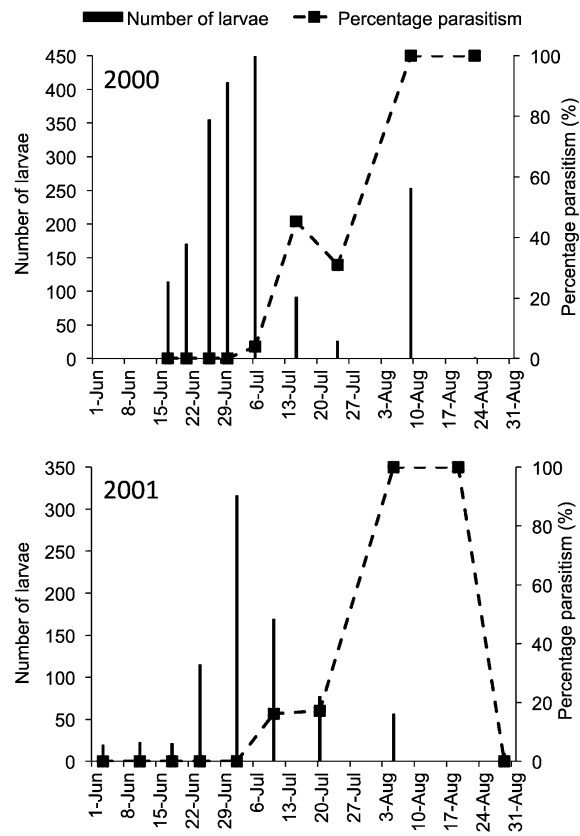

Figure 2. Percentage parasitism and number of larvae of Cassida nebulosa collected from Chenopodium album and C. album var. centrorubrum. Research was carried out in 2000 and 2001 in an experimental field of the Graduate School of Agricultural Science, Tohoku University, Japan.
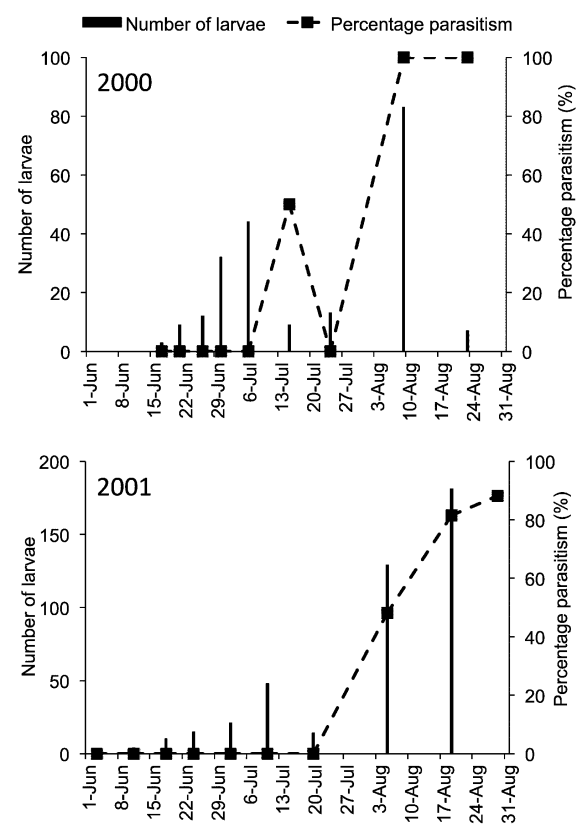

Figure 3. Percentage parasitism and number of larvae of Cassida piperata collected from Chenopodium album and C. album var. centrorubrum. research was carried out in 2000 and 2001 in an experimental field of the Graduate School of Agricultural Science, Tohoku University, Japan. 
high levels of parasitism, only a few adult beetles from the second generation were found. These results indicate that in this field study, populations of both C. nebulosa and C. piperata were highly restricted by the parasitoid $H$. rhosaces. To facilitate the research, the weeds in the study field were removed; therefore, the results might differ from natural parasitism. Since the larvae of Pieris napi were heavily parasitized on the host plants when the surrounding vegetation was artificially removed, while parasitism rate was low when the host plants were concealed by surrounding vegetation (natural condition) [11], the percentage parasitism determined in this study may be higher than that occurring under natural conditions.

\section{Acknowledgements}

I would like to thank Dr. Kazuaki Kamijo for providing the identification of the parasitoid wasps and other useful information.

\section{References}

[1] Kimoto, S. (1962) A Phylogenic Consideration of Chrysomelinae Based on Immature Stages of Japanese Species (Coleoptera). Journal of the Faculty Agriculture, 12, 67-116.

[2] Kimoto, S. and Takizawa, H. (1994) Leaf Beetles (Chrysomelidae) in Japan. Tokai University Press, Tokyo.

[3] Habu, A. (1960) A Revision of the Chalcididae (Hymenoptera) of Japan, with Descriptions of Sixteen New Species. Bulletin of the National Institute of Agricultural Sciences, Series C, 11, 131-363.

[4] Habu, A. (1962) Chalcididae, Leucospididae, and Podagrionidae (Insecta: Hymenoptera). Fauna Japonica. Biogeographical Society of Japan, Tokyo.

[5] Yamazaki, K. (2001) Cassida piperata (Coleoptera, Chrysomelidae): A New Host of Brachymeria inermis (Hymenoptera, Chalcididae). Elytra, 29, 40.

[6] Yamazaki, K. and Sugiura, S. (2002) A New Record of a Parasitoid Reared from the Tortoise Leaf Beetle Cassida piperata (Coleoptera, Chrysomelidae). Elytra, 30, 454.

[7] Nagasawa, A., Konno, Y. and Matsuda, K. (2003) New Record of Holcotetrastichus rhosaces (Walker) (Hymenoptera: Eulopidae), a Hymenopterous Parasitoid of Cassida nebulosa L. and C. piperata Hope (Coleoptera: Chrysomelidae), from Japan. Japanese Journal of Entomology, 6, 117-118.

[8] Domenichini, G. (1966) Hym. Eulophidae, Palearctic Tetrastichinae. In: Delucchi, V. and Remaudiere, G., Eds., Index of Entomohpagous Insects, Le François, Paris, 1-101.

[9] Graham, M.W.R.D.V. (1991) A Reclassification of the Europian Tetrastichinae: Revision of the Remaining Genera. Memoirs of the American Entomological Institute, 49, 1-322.

[10] Ikeda, E. (1997) Three Species of Tetrastichinae (Hymenoptera, Eulophidae), Newly Recorded from Japan. Japanese Journal of Entomology, 65, 186-192.

[11] Ohsaki, N. and Saito, Y. (1994) Food Plant Choice of Pieris Butterflies as A Trade-Off between Parasitoid Avoidance and Quality of Plants. Ecology, 75, 59-68. http://dx.doi.org/10.2307/1939382 
Scientific Research Publishing (SCIRP) is one of the largest Open Access journal publishers. It is currently publishing more than 200 open access, online, peer-reviewed journals covering a wide range of academic disciplines. SCIRP serves the worldwide academic communities and contributes to the progress and application of science with its publication.

Other selected journals from SCIRP are listed as below. Submit your manuscript to us via either submit@scirp.org or Online Submission Portal.
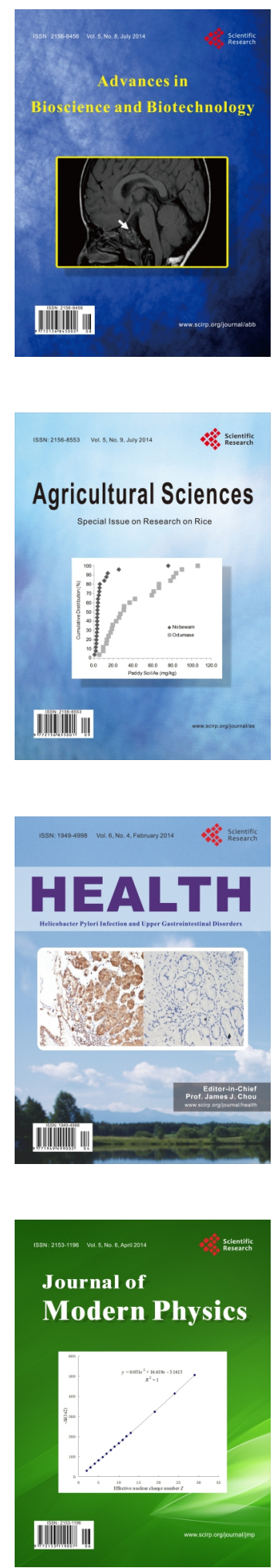
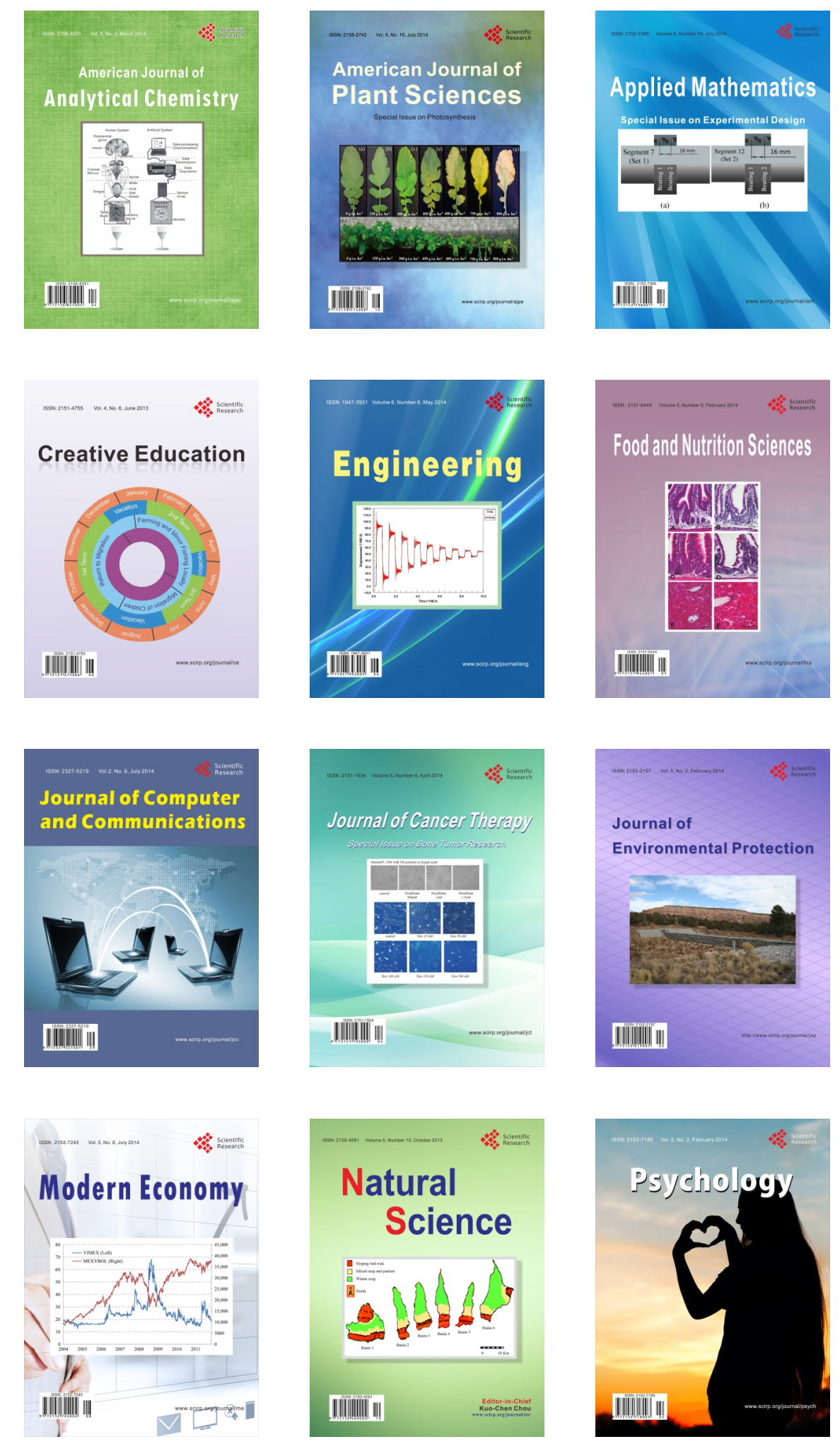